\title{
Melatonin modulates aromatase activity and expression in endothelial cells
}

\author{
VIRGINIA ALVAREZ-GARCÍA, ALICIA GONZÁLEZ, CARLOS MARTÍNEZ-CAMPA, \\ CAROLINA ALONSO-GONZÁLEZ and SAMUEL COS
}

Department of Physiology and Pharmacology, School of Medicine, University of Cantabria, 39011 Santander, Spain

Received December 13, 2012; Accepted February 4, 2013

DOI: $10.3892 / o r .2013 .2314$

\begin{abstract}
Melatonin is known to suppress the development of endocrine-responsive breast cancers by interacting with the estrogen signaling pathways. Paracrine interactions between malignant epithelial cells and proximal stromal cells are responsible for local estrogen biosynthesis. In human breast cancer cells and peritumoral adipose tissue, melatonin downregulates aromatase, which transforms androgens into estrogens. The presence of aromatase on endothelial cells indicates that endothelial cells may contribute to tumor growth by producing estrogens. Since human umbilical vein endothelial cells (HUVECs) express both aromatase and melatonin receptors, the aim of the present study was to evaluate the ability of melatonin to regulate the activity and expression of aromatase on endothelial cells, thus, modulating local estrogen biosynthesis. In the present study, we demonstrated that melatonin inhibits the growth of HUVECs and reduces the local biosynthesis of estrogens through the downregulation of aromatase. These results are supported by three lines of evidence. Firstly, $1 \mathrm{mM}$ of melatonin counteracted the testosterone-induced cell proliferation of HUVECs, which is dependent on the local biosynthesis of estrogens from testosterone by the aromatase activity of the cells. Secondly, we found that $1 \mathrm{mM}$ of melatonin reduced the aromatase activity of HUVECs. Finally, by real-time RT-PCR, we demonstrated that melatonin significantly downregulated the expression of aromatase as well as its endothelial-specific aromatase promoter region I.7. We conclude that melatonin inhibits aromatase activity and expression in HUVECs by regulating gene expression of specific aromatase promoter regions, thereby reducing the local production of estrogens.
\end{abstract}

\section{Introduction}

The pathogenesis and growth of breast cancer are linked to estrogens (1-3). High levels of estradiol found in some

Correspondence to: Dr Samuel Cos, Department of Physiology and Pharmacology, School of Medicine, University of Cantabria, Cardenal Herrera Oria s/n, 39011 Santander, Spain

E-mail: coss@unican.es

Key words: melatonin, pineal gland, aromatase, HUVECs breast tumors occur due to the uptake from the circulation or from in situ biosynthesis (4). One of the main pathways involved in the synthesis of estrogens in breast tumors is the aromatase pathway, which is responsible for the conversion of androgens into estrogens in extragonadal sites (5). The importance of the local biosynthesis of estrogens is highlighted by the high incidence of hormone-dependent breast cancer in postmenopausal women $(6,7)$ and, consequently, aromatase inhibitors have become a successful treatment in this disease $(8,9)$.

Melatonin, the main secretory product of the pineal gland, is widely known to reduce the growth and development of estrogen-responsive breast cancers (10-13). Melatonin exerts its oncostatic properties in hormone-dependent breast cancer by interfering at different levels with estrogen signaling pathways $(14,15)$. One of the mechanisms through which this occurs is based on the regulation by melatonin of both expression and activity of several enzymes, particularly aromatase which is involved in the biosynthesis of estrogens in the peripheral tissues; thus, melatonin behaves as a selective estrogen enzyme modulator $(16,17)$. In breast cancer cells which express aromatase (18) and the $\mathrm{MT}_{1}$ melatonin receptor $(19,20)$, melatonin inhibits aromatase activity and also downregulates aromatase expression at the transcriptional level (21). In vivo evidence of the modulator effect of melatonin on the enzyme aromatase has also been described in rats bearing dimethylbenzanthracene (DMBA)-induced mammary tumors (22).

Several lines of evidence highlight the contribution of the tumor microenvironment to tumor growth and maintenance. Adjacent adipose fibroblasts and vascular endothelial cells provide structural and biochemical support for tumor growth, mainly by increasing their estrogen biosynthesis in response to paracrine signals which are secreted by malignant breast epithelial cells in a phenomenon known as the desmoplastic reaction $(23,24)$. Recently, our group demonstrated that melatonin interferes in the desmoplastic reaction by inhibiting adipocyte differentiation and decreasing both the aromatase activity and expression in adipose fibroblasts, thereby reducing the number of cells contributing to estrogen production in the tumor adjacent tissue $(25,26)$. Adjacent adipose tissue surrounding malignant cells seems to account for the majority of aromatase expression in breast tumors $(5,24)$. Endothelial cells surrounding tumor cells, may provide another source of estrogens since they also express aromatase $(27,28)$. A 
single gene encodes aromatase and its expression is directed by alternative promoter use in a complex and tissue-specific manner $(29,30)$. Normal breast adipose tissue maintains low levels of aromatase expression, primarily via promoter I.4. However, in mammary cancer, aromatase levels are increased by the activation of promoters II and I.3 (31), both in malignant epithelial cells and adjacent adipose fibroblasts. Recent studies have led to the identification and characterization of the novel aromatase promoter I.7 which is upregulated in breast cancer tissue. This promoter contains endothelial cell-specific cisacting elements and its activity has been demonstrated in an endothelial cell line (32).

In human breast cancer cells (MCF-7), melatonin inhibits aromatase expression by decreasing the activity of promoters I.3 and II (33). The binding of melatonin to the $\mathrm{MT}_{1}$ receptor present in $\mathrm{MCF}-7$ cells has been described as a first step in the antiaromatase action of melatonin (34). Since vascular endothelial cells express aromatase and melatonin receptors $\left(\mathrm{MT}_{1}\right.$ and $\left.\mathrm{MT}_{2}\right)(35,36)$ and given the antiaromatase properties of melatonin, in the present study we explored the role of melatonin on the regulation of aromatase in the human umbilical vein endothelial cell line (HUVEC) and its contribution to local estrogen biosynthesis in the tumor microenvironment.

\section{Materials and methods}

Cells and culture conditions. Human umbilical vein endothelial cells (HUVECs) were purchased from the American Tissue Culture Collection (Rockville, MD, USA). They were maintained as monolayer cultures in $75-\mathrm{cm}^{2}$ plastic culture flasks in Vascular Cell Basal Medium (VCBM) (ATCC) supplemented with Endothelial Cell Growth Kit-BBE (ATCC) which consists of $2 \%$ fetal bovine serum (FBS), $0.2 \%$ bovine brain extract, $5 \mathrm{ng} / \mathrm{ml} \mathrm{rhEGF}, 10 \mathrm{mM}$ L-glutamine, $0.75 \mathrm{U} /$ $\mathrm{ml}$ heparin sulfate, $1 \mu \mathrm{g} / \mathrm{ml}$ hydrocortisone hemisuccinate, $50 \mu \mathrm{g} / \mathrm{ml}$ ascorbic acid, penicillin $(20 \mathrm{U} / \mathrm{ml})$ and streptomycin (20 $\mu \mathrm{g} / \mathrm{ml}$ ) (Sigma-Aldrich, Madrid, Spain) at $37^{\circ} \mathrm{C}$ in a humid atmosphere containing $5 \% \mathrm{CO}_{2}$. To avoid genetic mutation and low viability, no more than six passages of HUVECs were used for the following experiments.

Measurement of cellular proliferation. HUVECs were seeded into 96-multi-well plates at a density of $7 \times 10^{3}$ cells/well in VCBM supplemented with $2 \% \mathrm{FBS}$ and incubated at $37^{\circ} \mathrm{C}$. After $24 \mathrm{~h}$ of incubation, media were aspirated and replaced by fresh media supplemented with 5\% charcoal-stripped FBS (sFBS) and containing either $1 \mathrm{mM}, 10 \mu \mathrm{M}, 100 \mathrm{nM}, 1 \mathrm{nM}$ melatonin (Sigma-Aldrich) and/or $10 \mathrm{nM}$ estradiol (SigmaAldrich) and/or vehicle (ethanol at a final concentration $<0.0001 \%$ ). Cells were cultured for 3 days. Cell proliferation was measured by the MTT [3-(4,5-dimethylthiazol-2-yl)2,5-diphenyltetrazolium bromide] method, reading the absorbance at $570 \mathrm{~nm}$ in a microplate reader (Labsystems Multiskan RC 351; Vienna, VA, USA). MTT was obtained from Molecular Probes Inc. (Eugene, OR, USA).

Indirect measurement of aromatase activity. Indirect measurement of aromatase activity of HUVECs was obtained by evaluating cell proliferation in estrogen-free media in the presence of testosterone. Under these conditions, cell growth depends on the transformation of androgens to estrogens via the aromatase activity of the cells. To test this, HUVECs were seeded in 96-multi-well culture plates at a density of $7 \times 10^{3}$ cells/well in VCBM supplemented with $2 \% \mathrm{FBS}$ and incubated at $37^{\circ} \mathrm{C}$. After $24 \mathrm{~h}$ of incubation, media were replaced by others supplemented with $2 \%$ sFBS containing either testosterone (Sigma-Aldrich) $(1 \mu \mathrm{M})$, melatonin $(1 \mathrm{mM})$, the aromatase inhibitor aminoglutethimide (Sigma-Aldrich) $(100 \mu \mathrm{M})$ or vehicle (ethanol). Cell proliferation was assessed after 3 days of culture by using the MTT method.

Direct measurement of cellular aromatase activity. Aromatase activity in HUVECs was measured by the tritiated water release assay which is based on the formation of tritiated water during aromatization of a labeled androgenic substrate such as androst-4-ene-3,17-dione $\left[1 \beta-{ }^{3} \mathrm{H}(\mathrm{N})\right]$ (NEN Life Science Products, Boston, MA, USA) (37). HUVECs were seeded onto $75-\mathrm{cm}^{2}$ plastic culture flasks in VCBM supplemented with $2 \%$ FBS. When a homogenous monolayer of preconfluent HUVECs was reached, media were aspirated and replaced with serum-free media containing $300 \mathrm{nM}$ of the labeled substrate androst-4-ene-3,17-dione $\left[1 \beta-{ }^{3} \mathrm{H}(\mathrm{N})\right](75-80 \mathrm{Ci} / \mathrm{nM})$ in the presence of melatonin $(1 \mathrm{mM})$ or the diluent (ethanol). After $24 \mathrm{~h}$ of incubation, culture flasks were placed on ice for $15 \mathrm{~min}$ to condense any water vapor, and media were transferred to tubes containing $0.25 \mathrm{ml}$ ice-cold $30 \%$ tricholoroacetic acid $(\mathrm{w} / \mathrm{v})$, vortexed and centrifuged at $1700 \mathrm{x} \mathrm{g}$ for $20 \mathrm{~min}$. The supernatants were extracted with chloroform, vortexed and centrifuged at $1700 \mathrm{x} \mathrm{g}$ for $20 \mathrm{~min}$. The resulting aqueous supernatants were adsorbed with $10 \%$ dextran-coated charcoal (Sigma-Aldrich), vortexed, centrifuged at $1700 \mathrm{x}$ g for $20 \mathrm{~min}$. and the supernatants were added to vials with scintillation cocktail and counted in a beta counter (Beckman LS 6000 IC, Fullerton, CA, USA). The amount of radioactivity measured in $\left[{ }^{3} \mathrm{H}\right]$-water was corrected by substracting the blank values from each sample, obtained by incubating dishes containing medium with the tritiated androgen but no cells. The values were also corrected by taking into account the fractional retention of tritium in medium water throughout the processing, utilizing parallel dishes containing medium plus known amounts of $\left[{ }^{3} \mathrm{H}\right]$-water (NEN Life Science Products) through incubation and assay. The fractional retention of tritium in medium water throughout the incubation and processing of samples was consistently $>85 \%$.

Measurement of total aromatase mRNA and aromatase promoter region pI.7 gene expression. Analysis of the aromatase and aromatase promoter I.7 mRNA expression in HUVECs was carried out by real-time reverse transcription RT-PCR after incubation of cells with melatonin $(1 \mathrm{mM})$ or vehicle (ethanol) for $4 \mathrm{~h}$. The total cellular RNA was isolated from HUVECs and purified with the NucleoSpin RNA II kit (Macherey-Nagel, Düren, Germany) following the manufacturer's instructions. Integrity of RNA was assessed by electrophoresis in ethidium bromide-stained $1 \%$ agarose-Trisborate EDTA gels. The absorbance ratio $A_{260 \mathrm{~nm}} / \mathrm{A}_{280 \mathrm{~nm}}$ was $>1.8$. For cDNA synthesis, $1 \mu \mathrm{g}$ of total RNA was denatured at $65^{\circ} \mathrm{C}$ for $10 \mathrm{~min}$ and reverse transcribed for $50 \mathrm{~min}$ at $45^{\circ} \mathrm{C}$ with a cDNA synthesis kit (Bioline, London, UK) in a final volume 
Table I. Primers used for amplification of mRNA transcripts of human aromatase, aromatase promoter region pI.7 and s14 (control).

\begin{tabular}{llcc}
\hline mRNA & \multicolumn{1}{c}{ Sequence } & Product size (bp) & Primer concentration (nM) \\
\hline hAromatase FW & 5'-GTCGTGGACTTGGTCATGC-3' & 109 & 100 \\
hAromatase RV & 5'-CGAGTCTGTGCATCCTTCC-3' & & 100 \\
hpI.7 FW & 5'-AACACTCAGCTTTTTCCCAAC-3' & 100 & 200 \\
hpI.7 RV & 5'-CTTGCTGATTTCACCCCTTT-3' & & 200 \\
hs14 FW & 5'-TCCTGCGAGTGCTGTCAGAG-3' & 159 & 200 \\
hs14 RV & 5'-TCACCGCCCTACACATCAAAC-3' & & 200 \\
\hline
\end{tabular}

$\mathrm{FW}$, sense (forward) primer; RV, antisense (reverse) primer.
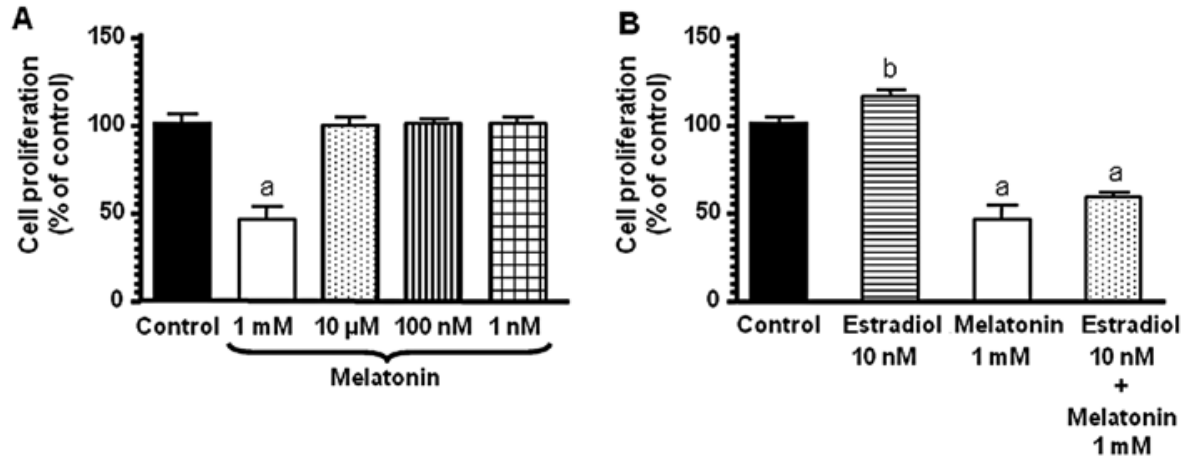

Figure 1. Effects of (A) melatonin (1 mM, $10 \mu \mathrm{M}, 100 \mathrm{nM}$ and $1 \mathrm{nM})$ and/or (B) 17ß-oestradiol $(10 \mathrm{nM})$ on HUVEC proliferation. Cells were seeded into 96-well culture plates (7,000 cells/well) in medium supplemented with $2 \%$ FBS for $24 \mathrm{~h}$. Then media were aspirated and replaced by fresh media supplemented with 5\% sFBS containing the indicated concentrations of melatonin and/or estradiol. After 3 days, cell proliferation was measured by the MTT method. Data are expressed as the percentage of the control group (mean \pm SEM). ${ }^{a} \mathrm{P}<0.001$ vs. control; ${ }^{b} \mathrm{P}<0.01$ vs. control.

of $20 \mu \mathrm{l}$ in the presence of $500 \mathrm{ng}$ of oligo(dT)12-18 primers. Primers used for amplification of aromatase and aromatase promoter I.7 (Sigma Genosys Ltd., Cambridge, UK), using the housekeeping gene s14, are listed in Table I. Real-time PCRs were performed in an MX3000 (Stratagene, La Jolla, CA, USA) using Brilliant ${ }^{\circledR}$ SYBR $^{\circledR}$ Green PCR Master Mix (Applied Biosystems, Madrid, Spain), following the manufacturer's instructions. Amplifications were performed for 40 cycles using the following temperature profile: $55^{\circ} \mathrm{C}$ for $45 \mathrm{sec}$ (annealing); $72^{\circ} \mathrm{C}$ for $30 \mathrm{sec}$ (extension) and $95^{\circ} \mathrm{C}$ for $30 \mathrm{sec}$ (denaturation).

Statistical analysis. The data are expressed as the means \pm standard errors of the mean (SEM) of six independent experiments. Statistical differences between groups were analyzed using one-way analysis of variance (ANOVA), followed by the Student-Newman-Keuls test. Results were considered as statistically significant at $\mathrm{P}<0.05$.

\section{Results}

Effects of melatonin on HUVEC proliferation. To investigate the effect of melatonin on HUVEC growth, cells were cultured in VCBM supplemented with 5\% sFBS in the presence of different concentrations of melatonin. Proliferation of HUVECs in the presence of melatonin $(1 \mathrm{mM})$ was signifi- cantly decreased while other concentrations of melatonin $(10 \mu \mathrm{M}, 100 \mathrm{nM}$ and $1 \mathrm{nM})$ had no effects (Fig. 1A). The addition of $17 \beta$-estradiol $(10 \mathrm{nM})$ into the media stimulated cell proliferation (Fig. 1B). This stimulatory effect of estradiol on cell proliferation was significantly counteracted by melatonin $(1 \mathrm{mM})$.

Effects of melatonin on testosterone-induced HUVEC proliferation as an indirect measurement of aromatase activity. Indirect evidence of aromatase activity in HUVECs was obtained by evaluating cell proliferation in estrogen-free media in the presence of testosterone (Fig. 2). Testosterone $(1 \mu \mathrm{M})$ significantly increased HUVEC proliferation $(\mathrm{P}<0.05)$ following culture for 3 days in media with sFBS. This stimulatory effect of testosterone was reduced $(\mathrm{P}<0.01)$ by the aromatase inhibitor aminoglutethimide $(100 \mu \mathrm{M})$, thus, indicating that, at least in part, cell proliferation was dependent on the formation of estrogens from testosterone by the aromatase activity of the cells. Melatonin $(1 \mathrm{mM})$ was also able to counteract the stimulatory effect of testosterone to values below those obtained by aminoglutethimide, which is indicative of an inhibitory effect on aromatase exerted by melatonin (Fig. 2).

Effects of melatonin on aromatase activity of HUVECs. The aromatase activity of HUVECs incubated for $24 \mathrm{~h}$ with tritiated 


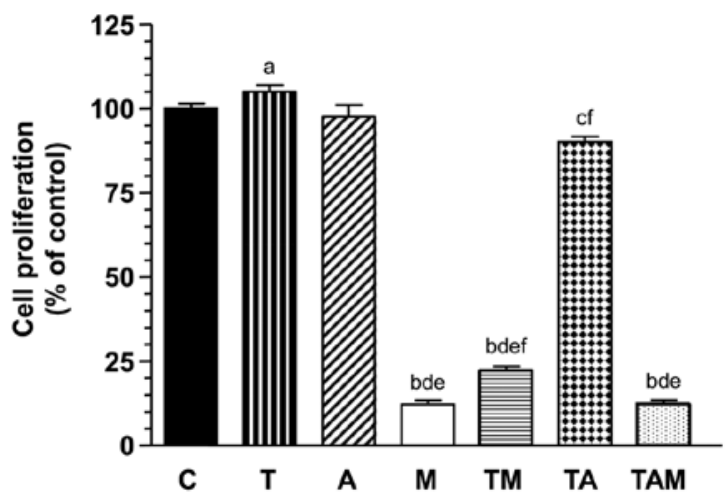

Figure 2. Indirect measurement of aromatase activity. Effects of $1 \mu \mathrm{M}$ testosterone (T), $1 \mathrm{mM}$ melatonin (M), $100 \mu \mathrm{M}$ aminoglutethimide (A), or vehicle (ethanol $0.0001 \%$ ) (C), either alone or in combination on HUVEC cell proliferation. Cells were seeded into 96 -well culture plates (7,000 cells/well) in medium supplemented with $2 \%$ FBS for $24 \mathrm{~h}$ and subsequently for 3 days in medium supplemented with $2 \%$ sFBS containing the above mentioned drugs. Data are expressed as the percentage of the control group (means \pm SEM). ${ }^{\text {a }} \mathrm{P}<0.05$ vs. $\mathrm{C}$; ${ }^{\mathrm{P}} \mathrm{P}<0.001$ vs. $\mathrm{C} ;{ }^{\mathrm{c}} \mathrm{P}<0.01$ vs. $\mathrm{T} ;{ }^{\mathrm{d}} \mathrm{P}<0.001$ vs. $\mathrm{T} ;{ }^{\mathrm{e}} \mathrm{P}<0.001$ vs. $\mathrm{A}$; ${ }^{\mathrm{f}} \mathrm{P}<0.05$ vs. $\mathrm{M}$.

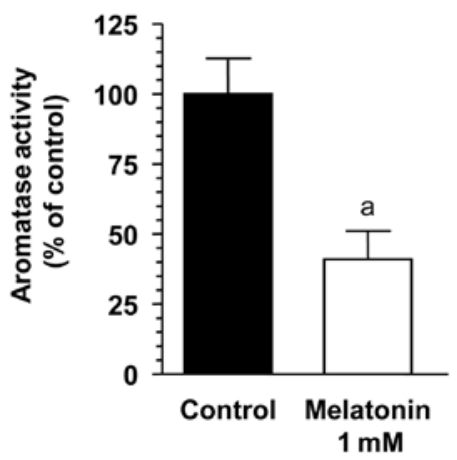

Figure 3. Effects of melatonin $(1 \mathrm{mM})$ or the diluent (ethanol $0.0001 \%$ ) on the aromatase activity of HUVECs. Cells were seeded onto $75-\mathrm{cm}^{2}$ plastic culture flasks in VCBM supplemented with $2 \%$ FBS. When a homogeneous monolayer of preconfluent cells was reached, media were aspirated and replaced by serum-free media containing tritiated androstenedione in the presence of melatonin $(1 \mathrm{mM})$ or vehicle. Aromatase activity was determined after $24 \mathrm{~h}$ of incubation, as described in Materials and methods. Data are expressed as the percentage of the control group (means $\pm \mathrm{SEM}$ ). ${ }^{\mathrm{a}} \mathrm{P}<0.01$ vs control.

androstenedione was estimated by the formation of tritiated water. Melatonin at pharmacological concentrations $(1 \mathrm{mM})$ significantly decreased the aromatase activity of HUVECs $(\mathrm{P}<0.01)$ (Fig. 3). Melatonin $(1 \mathrm{mM})$ induced a significant $60 \%$ inhibition of the aromatase activity of the HUVECs.

Effects of melatonin on total aromatase mRNA and aromatase promoter region $\mathrm{pI} .7$ expression. With the aim of determining whether the inhibitory effect of melatonin on aromatase activity is due to the downregulation of aromatase expression, we incubated HUVECs with either melatonin $(1 \mathrm{mM})$ or vehicle for $4 \mathrm{~h}$, and total RNA was isolated to perform real-time quantitative PCR with specific primers for human aromatase. As a control, the same samples were subjected to real-time quantitative PCR with specific primers for the housekeeping gene s14, a ribosomal protein component of the 40 S subunit.
A

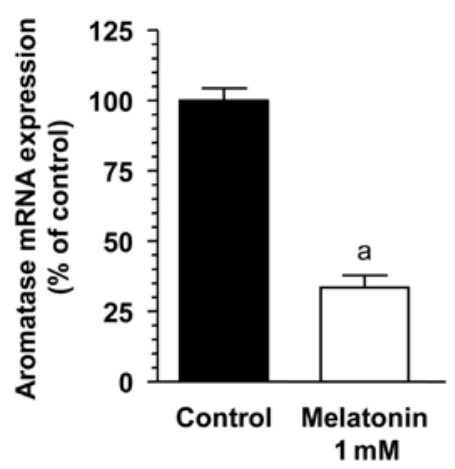

B

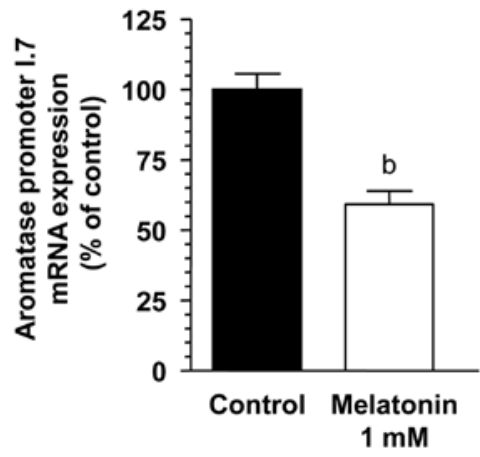

Figure 4. Effects of melatonin on (A) total aromatase mRNA and (B) aromatase promoter I.7 mRNA expression in HUVECs. Cells were incubated with melatonin $(1 \mathrm{mM})$ or ethanol $(0.0001 \%)$ for $4 \mathrm{~h}$. Total mRNA was extracted from HUVECs and reverse transcribed. cDNA was subjected to PCR using specific primers for human aromatase, aromatase promoter I.7 or s14. Data are expressed as the percentage of the control group (means \pm SEM). ${ }^{\mathrm{a}} \mathrm{P}<0.001$ vs. control; ${ }^{\mathrm{b}} \mathrm{P}<0.01$ vs. control.

Melatonin treatment $(1 \mathrm{mM})$ exhibited a significant and potent inhibition (65\%) in aromatase mRNA expression in HUVECs (Fig. 4A).

To determine whether aromatase promoter I.7, an aromatase promoter mainly active in vascular endothelial cells in breast cancer, is involved in the melatonin regulation of aromatase expression, we used real-time quantitative PCR to amplify the aromatase endothelial-specific promoter I.7 transcripts from RNA extracted from HUVECs. As shown in Fig. 4B, melatonin $(1 \mathrm{mM})$ significantly $(\mathrm{P}<0.01)$ downregulated the gene expression of the aromatase promoter I.7.

\section{Discussion}

The relevance of estrogens in the growth and pathogenesis of hormone-dependent breast cancer is supported by extensive experimental and epidemiological evidence (1-3). In premenopausal non-pregnant women, estrogen synthesis occurs mainly in the ovary. However, in postmenopausal women local estrogen biosynthesis in extraovarian sites has great relevance. Extraovarian estrogen biosynthesis is directed by different enzymes (aromatase, sulfatase) which transform androgens into estrogens as well as compounds of weak estrogenic activity into more active forms. All of these locally produced steroid hormones contribute to the genesis and development of breast tumors as well as other types of tumors such as endometrial and ovary carcinoma $(24,38)$. Targeting aromatase has proven beneficial in treating breast cancer, and aromatase 
inhibitors are being used clinically as chemotherapeutic agents for hormone-dependent breast cancer $(9,39)$.

Melatonin, the main pineal hormone, is well known for its oncostatic properties $(10,11,40)$. This indoleamine exerts its oncostatic effects on estrogen-dependent breast tumors mainly by two mechanisms: interfering with the estrogen signaling pathways at the estrogen receptor level $(41,42)$ and regulating both the activity and expression of the enzymes involved in local estrogen biosynthesis. In relation with the modulator effect of melatonin on the aromatase enzyme, it is known that melatonin inhibits aromatase activity and expression in vitro in human breast cancer cells (21), as well as in vivo in rats bearing DMBA-induced mammary tumors (22). Since in breast cancer tissue aromatase expression in stromal cells adjacent to tumor cells seems to account for the majority of aromatase expression in breast tumors, and because it is known that melatonin decreases the aromatase activity and expression in adipose fibroblasts surrounding malignant cells $(25,26)$, in this study, we investigated whether melatonin is able to regulate the production of estrogens in endothelial cells. To accomplish this, we used HUVECs which are known to express aromatase $(27,28)$ and melatonin receptors $\left(\mathrm{MT}_{1}\right.$ and $\left.\mathrm{MT}_{2}\right)(36)$.

According to previous findings (35), melatonin (1 mM) added to the culture decreased HUVEC growth. This melatonin concentration reduced HUVEC proliferation by $50 \%$ after 3 days of culture. Interestingly, the addition of estradiol (10 nM) significantly increased HUVEC growth and melatonin $(1 \mathrm{mM})$ counteracted this stimulatory effect. This finding is consistent with the proangiogenic effects of estradiol that have been described by other authors both in vivo and in vitro (43) and is a consequence of the presence of estrogen receptors in endothelial cells, which enables the response to this hormone. The present study demonstrated that melatonin at a 1-mM concentration reduced the synthesis of estrogens in HUVECs through the inhibition of aromatase, the enzyme that catalyzes the rate-limiting step in the conversion of androgens to estrogens (18). These results are supported by three types of experiments. In the first experimental series, we demonstrated that melatonin $(1 \mathrm{mM})$ counteracted the stimulatory effects of testosterone on HUVEC growth cultured in estrogen-free media. Under these conditions, the proliferative effects of testosterone depend on the local biosynthesis of estrogens from testosterone carried out by the aromatase activity of the cells. Thus, the inhibitory effects of melatonin could be due to its antiaromatase activity. In a second series of experiments, we directly measured the aromatase activity of HUVECs by the tritiated water release assay, finding that this was reduced by melatonin at a $1-\mathrm{mM}$ concentration, which is the same concentration that gives the highest antiproliferative effects in HUVECs. Finally, we evaluated the possible role of melatonin on the modulation of aromatase at the transcriptional level in HUVECs and we demonstrated that $1 \mathrm{mM}$ of melatonin induced a marked decrease in the expression of mRNA aromatase in the HUVECs.

To our knowledge, this is the first time that the effects of melatonin on aromatase activity and expression in endothelial cells have been established. However, the antiaromatase properties of melatonin have been solidly described in several other cell lines. Melatonin modulates the transformation of androgens to estrogens in breast cancer cells and adjacent adipose fibroblasts as well as in glioma cells through the inhibition of aromatase activity and expression $(26,44,45)$. The aromatase enzyme is encoded by one single gene and its tissue-specific expression is regulated by alternative splicing mechanisms (29). In the disease-free breast, aromatase is expressed in the mammary adipose tissue mainly by the relatively weak promoter I.4. However, in breast cancer tissue, both in malignant epithelial cells and surrounding fibroblasts, aromatase expression is mainly driven by the activation of promoters I.3 and II (31). In human breast cancer cells (MCF-7), melatonin inhibits aromatase expression by decreasing the activity of promoters I.3 and II (33). In vascular endothelial cells of breast cancer, promoter I.7 has been identified, which is a novel breast cancer-associated aromatase promoter mainly active in vascular endothelial cells in breast cancer. Promoter I.7 contains a crucial GATA-binding site characteristic of a promoter of endothelial cell origin (32) even though it is also present in adipose tissue adjacent to breast tumors (43). Excessive aromatase expression via promoters I.3, II and I.7 and the consequent increase in estrogen biosynthesis in malignant epithelial cells, undifferentiated adipose fibroblasts and adjacent endothelial cells contribute to the development and progression of breast cancer. This study shows that melatonindependent regulation of aromatase gene expression occurs mainly through downregulation of gene expression of the specific aromatase promoter region I.7 in HUVECs. Extensive angiogenesis, which consists of the formation of new blood vessels from existing endothelium, is a hallmark of aggressive tumor growth (46). The ability of estrogens to stimulate angiogenesis has been well-established (43). Overexpression of aromatase from aromatase promoter I.7 in vascular endothelial tissue surrounding breast tumors may contribute to the growth of breast cancer by two mechanisms. Firstly, the elevated in situ aromatase activity may increase the local estrogen concentration thus directly affecting tumoral growth. Secondly, the high estrogen concentration would presumably promote angiogenesis.

The effects of melatonin on cancer cells are dependent on melatonin concentrations, duration of exposure and the characteristics of cells being tested. In the present study, only pharmacological concentrations of melatonin were effective. In previous studies $(10,11,16,21)$, a strong inhibitory effect induced by nanomolar concentrations of melatonin on human breast cancer cells was described. However, high concentrations of melatonin are necessary to obtain oncostatic actions in other types of normal and cancer cells $(25,26,35,36,47,48)$. Melatonin is a highly lipid-soluble indolamine which may easily cross the blood-brain barrier, and there is evidence that the melatonin concentration in the cerebrospinal fluid is higher than that in blood (49). Melatonin is also 3 -fold more concentrated in neoplastic and adipose tissue of the breast (50). These high concentrations of melatonin in certain tissues may contribute towards the explanation of why high levels of melatonin are necessary to obtain various oncostatic actions of melatonin.

The findings present herein point to a role of melatonin in mediating the aromatase activity and expression in human endothelial cells by regulating the gene expression of specific aromatase promoter regions. Since the enzymes responsible for estrogen biosynthesis in tumoral tissue constitute a 
pharmacological target by which to selectively reduce the effects of estrogens in hormone-dependent cancers, the development of drugs that inhibit these enzymes is currently a major strategy for treating and preventing carcinogenesis. Antiaromatase properties of the pineal hormone make melatonin an attractive compound to be tested for its possible therapeutic value in breast cancer.

\section{Acknowledgements}

This study was supported by a grant from the Spanish MICINN (SAF2010-19579).

\section{References}

1. Russo IH and Russo J: Role of hormones in mammary cancer initiation and progression. J Mammary Gland Biol Neoplasia 3: 49-61, 1998.

2. Russo $\mathrm{J}$ and Russo IH: The role of estrogen in the initiation of breast cancer. J Steroid Biochem Mol Biol 102: 89-96, 2006.

3. Orlando L, Schiavone P, Fedele P, et al: Molecularly targeted endocrine therapies for breast cancer. Cancer Treat Rev 36 (Suppl 3): S67-S71, 2010.

4. Landeghem AA, Poortman J, Nabuurs M and Thijssen JH: Endogenous concentration and subcellular distribution of estrogens in normal and malignant human breast tissue. Cancer Res 45: 2900-2906, 1985.

5. Bulun SE, Lin Z, Imir G, et al: Regulation of aromatase expression in estrogen-responsive breast and uterine disease: from bench to treatment. Pharmacol Rev 57: 359-383, 2005.

6. Bulun SE, Price TM, Aitken J, Mahendroo MS and Simpson ER: A link between breast cancer and local estrogen biosynthesis suggested by quantification of breast adipose tissue aromatase cytochrome P450 transcripts using competitive polymerase chain reaction after reverse transcription. J Clin Endocrin Metab 77: 1622-1628, 1993.

7. Yue W, Wang JP, Hamilton CJ, Demers LM and Santen RJ: In situ aromatization enhances breast tumor estradiol levels and cellular proliferation. Cancer Res 58: 927-932, 1998.

8. Santen RJ and Harvey HA: Use of aromatase inhibitors in breast carcinoma. Endocr Relat Cancer 6: 75-92, 1999.

9. Brodie AM and Njar VC: Aromatase inhibitors and their application in breast cancer treatment. Steroids 65: 171-179, 2000.

10. Hill SM and Blask DE: Effects of the pineal hormone melatonin on the proliferation and morphological characteristics of human breast cancer cells (MCF-7) in culture. Cancer Res 48: 6121-6126, 1988.

11. Cos S and Sánchez-Barceló EJ: Melatonin and mammary pathological growth. Front Neuroendocrinol 21: 133-170, 2000.

12. Blask DE, Sauer LA and Dauchy RT: Melatonin as a chronobiotic/anticancer agent: cellular, biochemical and molecular mechanisms of action and their implications for circadian-based cancer therapy. Curr Topics Med Chem 2: 113-132, 2002.

13. Mediavilla MD, Sánchez-Barceló EJ, Tan DX, Manchester L and Reiter RJ: Basic mechanisms involved in the anti-cancer effects of melatonin. Curr Med Chem 17: 4462-4481, 2010.

14. Sánchez-Barceló EJ, Cos S, Fernández R and Mediavilla MD: Melatonin and mammary cancer: a short review. Endocr Relat Cancer 10: 153-159, 2003.

15. Cos S, González A, Martínez-Campa C, Mediavilla MD, Alonso-González C and Sánchez-Barceló EJ: Estrogen-signaling pathway: a link between breast cancer and melatonin oncostatic actions. Cancer Detect Prev 30: 118-128, 2006.

16. Cos S, González A, Martínez-Campa C, Mediavilla MD Alonso-González C and Sánchez-Barceló EJ: Melatonin as a selective estrogen enzyme modulator. Curr Cancer Drug Targets 8: 691-702, 2008.

17. González A, Cos S, Martínez-Campa C, Alonso-González C, Sánchez-Mateos S, Mediavilla MD and Sánchez-Barceló EJ: Selective estrogen enzyme modulator actions of melatonin in human breast cancer cells. J Pineal Res 45: 86-92, 2008.

18. Zhou D, Wang J, Chen E, Murai J, Siiteri PK and Chen S: Aromatase gene is amplified in MCF-7 human breast cancer cells. J Steroid Biochem Mol Biol 46: 147-153, 1993.
19. Ram PT, Kiefer T, Silverman M, Song Y, Brown GM and Hill SM: Estrogen receptor transactivation in MCF-7 breast cancer cells by melatonin and growth factors. Mol Cell Endocrinol 141: 53-64, 1998.

20. Ram PT, Dai J, Yuan L, Dong C, Kiefer TL, Lai L and Hill SM: Involvement of the mt 1 melatonin receptor in human breast cancer. Cancer Lett 179: 141-150, 2002.

21. Cos S, Martínez-Campa C, Mediavilla MD and SánchezBarceló EJ: Melatonin modulates aromatase activity in MCF-7 human breast cancer cells. J Pineal Res 38: 136-142, 2005.

22. Cos S, González A, Güezmes A, Mediavilla MD, MartínezCampa C, Alonso-González C and Sánchez-Barceló EJ: Melatonin inhibits the growth of DMBA-induced mammary tumors by decreasing the local biosynthesis of estrogens through the modulation of aromatase activity. Int J Cancer 118: 274-278, 2006.

23. Meng L, Zhou J, Sasano H, Suzuki T, Zeitoun KM and Bulun SE: Tumor necrosis factor $\alpha$ and interleukin 11 secreted by malignant breast epithelial cells inhibit adipocyte differentiation by selectively down-regulating CCAAT/enhancer binding protein $\alpha$ and peroxisome proliferator-activated receptor $\gamma$ : mechanism of desmoplastic reaction. Cancer Res 61: 2250-2255, 2001.

24. Bulun SE, Chen D, Lu M, et al: Aromatase excess in cancers of breast, endometrium and ovary. J Steroid Biochem Mol Biol 106: 81-96, 2007.

25. Alvarez-García V, González A, Alonso-González C, MartínezCampa $\mathrm{C}$ and Cos S: Melatonin interferes in the desmoplastic reaction in breast cancer by regulating cytokine production. $\mathrm{J}$ Pineal Res 52: 282-290, 2012

26. González A, Alvarez-García V, Martínez-Campa C, AlonsoGonzález $\mathrm{C}$ and $\operatorname{Cos} \mathrm{S}$ : Melatonin promotes differentiation of 3T3-L1 fibroblasts. J Pineal Res 52: 12-20, 2012.

27. Harada N, Sasano H, Murakami H, Ohkuma T, Nagura H and Takagi Y: Localized expression of aromatase in human vascular tissues. Circ Res 84: 1285-1291, 1999.

28. Mukherjee TK, Dinh H, Chaudhuri G and Nathan L: Testosterone attenuates expression of vascular cell adhesion molecule-1 by conversion to estradiol by aromatase in endothelial cells: implications in atherosclerosis. Proc Natl Acad Sci USA 6: 4055-4060, 2002.

29. Sebastian S and Bulun SE: A highly complex organization of the regulatory region of the human CYP19 (aromatase) gene revealed by the human genome project. J Clin Endocrinol Metab 10: 4600-4602, 2001.

30. Bulun SE, Lin Z, Zhao H, Lu M, Amin S, Reierstad S and Chen D: Regulation of aromatase expression in breast cancer tissue. Ann NY Acad Sci 1155: 121-131, 2009.

31. Chen D, Reierstad S, Lu M, Lin Z, Ishikawa H and Bulun SE: Regulation of breast cancer-associated aromatase promoters. Cancer Lett 273: 15-27, 2009

32. Sebastian S, Takayama K, Shozu M and Bulun SE: Cloning and characterization of a novel endothelial promoter of the human CYP19 (aromatase P450) gene that is up-regulated in breast cancer tissue. Mol Endocrinol 10: 2243-2254, 2002.

33. Martínez-Campa C, González A, Mediavilla MD, AlonsoGonzález C, Álvarez-García V, Sánchez-Barceló EJ and Cos S: Melatonin inhibits aromatase promoter expression by regulating cyclooxygenases expression and activity in breast cancer cells. $\mathrm{Br}$ J Cancer 101: 1613-1619, 2009.

34. González A, Martínez-Campa C, Mediavilla MD, et al: Effects of $\mathrm{MT}_{1}$ melatonin receptor overexpression on the aromatasesupressive effect of melatonin in MCF-7 human breast cancer cells. Oncol Rep 4: 947-953, 2007.

35. Cui P, Luo Z, Zhang H, et al: Effect and mechanism of melatonin's action on the proliferation of human umbilical vein endothelial cells. J Pineal Res 4: 358-362, 2006.

36. Cui P, Yu M, Luo Z, Dai M, Han J, Xiu R and Yang Z: Intracellular signaling pathways involved in cell growth inhibition of human vein endothelial cells by melatonin. J Pineal Res 44: 107-114, 2008.

37. Ackerman GE, Smith ME, Mendelson CR, MacDonald PC and Simpson ER: Aromatization of androstenedione by human adipose tissue stromal cells in monolayer culture. J Clin Endocrinol Metab 53: 412-417, 1981.

38. Pasqualini JR: The selective estrogen enzyme modulators in breast cancer: a review. Biochim Biophys Acta 1654: 123-143, 2004.

39. Pasqualini JR and Chetrite GS: Recent insight on the control of enzymes involved in estrogen formation and transformation in human breast cancer. J Steroid Biochem Mol Biol 93: 221-236, 2005. 
40. Cos S and Sánchez-Barceló EJ: Melatonin, experimental basis for a possible application in breast cancer prevention and treatment. Histol Histopathol 15: 637-647, 2000.

41. Molis TM, Spriggs LI and Hill SM: Modulation of estrogen receptor mRNA expression by melatonin in MCF-7 human breast cancer cells. Mol Endocrinol 8: 1681-1690, 1994.

42. Hill SM, Spriggs LL, Simon MA, Muraoka H and Blask DE: The growth inhibitory action of melatonin on human breast cancer cells is linked to the estrogen response system. Cancer Lett 64: 249-256, 1992.

43. Garvin S, Nilsson UW and Dabrosin C: Effects of oestradiol and tamoxifen on VEGF, soluble VEGFR-1 and VEGFR-2 in breast cancer and endothelial cells. Br J Cancer 9: 1005-1010, 2005.

44. González A, Martínez-Campa C, Mediavilla MD, AlonsoGonzález C, Sánchez-Barceló EJ and Cos S: Inhibitory effects of pharmacological doses of melatonin on aromatase activity and expression in rat glioma cells. Br J Cancer 97: 755-760, 2007.

45. Knower KC, To SQ, Takagi K, Miki Y, Sasano H, Simpson ER and Clyne CD: Melatonin suppresses aromatase expression and activity in breast cancer associated fibroblasts. Breast Cancer Res Treat 132: 765-771, 2012 .
46. Turner HE, Harris AL, Melmed S and Wass JA: Angiogenesis in endocrine tumors. Endocr Rev 24: 600-632, 2003.

47. García-Santos G, Antolín I, Herrera F, Martín V, RodriguezBlanco J, del Pilar Carrera M and Rodriguez C: Melatonin induces apoptosis in human neuroblastoma cancer cells. J Pineal Res 41: 130-135, 2006.

48. Sainz RM, Mayo JC, Tan DX, Leon J, Manchester L and Reiter RJ: Melatonin reduces prostate cancer cell growth leading to neuroendocrine differentiation via a receptor and PKA independent mechanism. Prostate 63: 29-43, 2005.

49. Longatti P, Perin A, Rizzo V, Comai S, Giusti P and Costa CV: Ventricular cerebrospinal fluid melatonin concentrations investigated with an endoscopic technique. J Pineal Res 42: 113-118, 2007.

50. Maestroni GJ and Conti A: Melatonin in human breast cancer tissue: association with nuclear grade and estrogen receptor status. Lab Invest 75: 557-561, 1996. 